\title{
IMPLANTAÇÃO DE POLÍTICA DE EDUCAÇÃO PERMANENTE EM SAÚDE NO RIO GRANDE DO SUL
}

\author{
IMPLEMENTATION OF A CONTINUING EDUCATION IN HEALTH POLICY IN RIO GRANDE DO SUL, BRAZIL \\ IMPLANTACIÓN DE UNA POLÍTICA DE EDUCACIÓN PERMANENTE EN SALUD EN RIO GRANDE DO \\ SUL, BRASIL
}

\author{
Hedi Berwaldt Daniel ${ }^{1}$ \\ Juliana Vieira de Araujo Sandri ${ }^{2}$ \\ Luciana Peter Grillo ${ }^{3}$
}

Resumo A Política Nacional de Educação Permanente em Saúde foi instituída em 2004 como estratégia do Sistema Único de Saúde para a formação de recursos humanos. Uma portaria do Ministério da Saúde definiu diretrizes para a sua implementação, fortalecendo as escolas técnicas do Sistema Único de Saúde como instituições prioritárias na articulação e execução da formação de trabalhadores do nível médio. Este artigo foi elaborado com base em resultados de pesquisa qualitativa. A coleta de dados constituiu-se da análise temática dos documentos das oficinas de sensibilização e das entrevistas aplicadas a gestores regionais, estaduais e técnicos das coordenadorias regionais de saúde que participaram de oficinas de sensibilização, além de técnicos da Escola Estadual de Educação Profissional em Saúde do Rio Grande do Sul. Os resultados indicam que eles tinham conhecimentos sobre a portaria e que as potencialidades estavam no financiamento federal, no acesso ao Colegiado de Gestão Regional e no comprometimento dos envolvidos. Já as dificuldades eram a falta de recursos humanos na Secretaria de Estado de Saúde, ocasionando sobrecarga de trabalho; o fato de a escola não ser descentralizada e não estar credenciada no estado; a liberação dos trabalhadores municipais para formação e entraves operacionais na execução de recursos financeiros no estado.

Palavras-chave educação permanente; escola técnica; Sistema Único de Saúde.
Abstract The National Policy on Continuing Education in Health was established in 2004 as the National Health System's strategy for human resource training. A Ministry of Health ordinance set guidelines for its implementation, reinforcing the technical Health System schools as priority institutions in coordinating and implementing the training of mid-level workers. This article was based on the results of a qualitative survey. Data collection consisted of the thematic analysis of documents originating from the awareness raising workshops and from interviews applied to regional, state, and technical managers of the regional health departments who attended the workshops, in addition to technicians from the State School of Professional Education in Health of Rio Grande do Sul (Brazil). The results indicate that they had knowledge of the ordinance and that the potential was in federal funding, access to the Regional Management Board, and in the commitment of those involved. The difficulties, meanwhile, were the lack of human resources in the State Department of Health, causing work overload; the fact that the school is neither decentralized nor accredited by the state; the release of municipal workers for training, and operational barriers in the implementation of financial resources in the state.

Keywords permanent education; technical school; Unified Health System. 


\section{Introdução}

Ao Sistema Único de Saúde (SUS) foi atribuída a função de "ordenar a formação de recursos humanos na área da saúde" (Brasil, 2002, p. 120). Contudo, ele ainda enfrenta problemas, resultantes de demandas específicas da assistência, dos processos intersetoriais e de gestão que mobilizam a administração pública, principalmente em relação à formação de seus trabalhadores (Campos et al., 2006).

Para Lopes e colaboradores (2007), na década de 1970 a Organização Pan-Americana da Saúde iniciou estudos que resultaram na proposta de educação permanente pautada na aproximação entre ensino e serviço. Tal proposição embasou a Política de Educação Permanente (PEP) no Brasil.

A PEP tem como princípio basilar qualificar os profissionais da saúde, com o intuito de melhorar a assistência prestada e modificar a atenção de um modelo biologicista para um modelo preventivista. Conforme Haddad e colaboradores (2008), no Brasil se tornou necessário modificar práticas antigas, centradas na doença e desarticuladas do sistema público vigente.

Segundo Campos e colaboradores (2006, p. 43), o conceito de educação permanente pressupõe a "noção de aprendizagem significativa, que vincula o aprendizado a elementos que façam sentido para os sujeitos envolvidos, de modo que os processos de capacitação sejam estruturados a partir da problematização dos processos de trabalho".

Em reconhecimento à importância de articular a educação e a regulação da força de trabalho nos serviços do setor, o Ministério da Saúde (MS) criou em 2003 a Secretaria de Gestão do Trabalho e Educação na Saúde, conferindo a ela a missão de integrar o ensino com o trabalho em saúde para motivar e propor mudanças na formação técnica, na graduação e na pós-graduação e promover um processo de educação permanente dos trabalhadores do SUS, com base nas necessidades de saúde da população (Brasil, 2003; Haddad et al., 2008).

Em 2004, por meio da portaria GM/MS 198 (Brasil, 2004a), foi instituída a Política Nacional de Educação Permanente em Saúde (Pneps) como uma proposta de ação estratégica, visando contribuir para transformar e qualificar as práticas de saúde, a organização das ações e dos serviços de saúde, os processos formativos e as práticas pedagógicas na formação e no desenvolvimento de trabalhadores do setor.

Cabe lembrar que a Lei de Diretrizes e Bases da Educação Nacional (LDB) expressa que a educação "tem por finalidade o pleno desenvolvimento do educando, seu preparo para o exercício da cidadania e sua qualificação para o trabalho" e que um dos seus princípios é a "vinculação entre a educação escolar, o trabalho e as práticas sociais" (Brasil, 1996a, p. 27.833).

Inserida na Educação Permanente está a Educação Profissional, também chamada de Ensino Técnico de Nível Médio (LDB - lei 9.394, de 20 de 
dezembro de 1996), que tem como objetivo não só a formação, mas também a qualificação, a requalificação, a reprofissionalização para trabalhadores em qualquer escolaridade, atualização tecnológica permanente e habilitação nos níveis médio e superior. Educação profissional é um conceito de ensino abordado pela Lei de Diretrizes e Bases da Educação (lei n. 9.394, de 20 de dezembro de 1996), complementado pelo decreto n. 2.208, de 17 de abril de 1997 (Brasil, 1997), e reformado pelo decreto n. 5.154, de 23 de julho de 2004 (Brasil, 2004b).

Em 2007, pela portaria GM/MS 1.996 (Brasil, 2007a), o Ministério da Saúde definiu novas diretrizes e estratégias para a implementação da Pneps, compondo uma base normativa para a organização dos processos de gestão da educação na saúde nas diferentes esferas. Para fortalecer a formação técnica do pessoal de nível médio que atua no setor, criou-se a Rede de Escolas Técnicas do SUS (RET-SUS), formada por 37 unidades, as ETSUS (Galvão et al., 2006), consideradas instituições prioritárias na articulação e na execução da Política de Educação Permanente em Saúde (Peps).

Também em 2007 iniciaram-se no Rio Grande do Sul os trabalhos da ETSUS, que ainda estão em fase de estruturação nas diferentes regiões do estado. Esse processo envolve uma ampla rede de instituições e profissionais e depende de procedimentos administrativos, burocráticos e técnicos que por vezes dificultam o desenvolvimento de ações e tornam morosa a dinâmica de implementação da Peps.

\section{A ETSUS e a Pneps no Rio Grande do Sul}

De acordo com Machado, Daniel e Reinhardt (2008), a ETSUS foi implantada no Rio Grande do Sul em maio de 2007 e desde então vem cumprindo as etapas legais estabelecidas para credenciamento e aprovação dos cursos pelo Conselho Estadual de Educação (CEED). A criação da escola recebeu parecer favorável do CEED em janeiro de 2008, e o decreto de criação foi publicado em março do mesmo ano. Inserida no organograma da Secretaria Estadual da Saúde, atualmente ela está vinculada à Escola de Saúde Pública (ESP) do estado.

Para o funcionamento como escola autorizada pelo Ministério da Educação, a ETSUS precisa credenciar-se no CEED, mas antes é preciso organizar instalações, equipamentos e corpo técnico-pedagógico habilitado para exercer as atividades docentes.

Diante da abrangência e da complexidade de se instituir como órgão responsável pela gestão e pela execução de uma Política de Educação Profissional em Saúde, a ETSUS/RS propõe-se a avançar em sua forma de organização curricular e gestão descentralizada, por considerar que é a melhor forma para o desenvolvimento da formação técnica de nível médio, levando em conta 
os perfis e as competências exigidas para o enfrentamento e a resolutividade da problemática da saúde no estado (Machado, Daniel e Reinhardt, 2008).

O estado segue o que determina a portaria GM/MS 1.996/2007: “A condução regional da Política Nacional de Educação Permanente em Saúde se dará por meio dos Colegiados de Gestão Regional (CGR), com a participação das Comissões Permanentes de Integração Ensino-Serviço (CIES)" (Brasil, 2007a, p. 8).

O CGR - denominado Cogere no Rio Grande do Sul - é a instância de pactuação permanente e cogestão solidária e cooperativa. É composto pelos gestores municipais de saúde de determinada região, com a representação do gestor estadual. Com relação à administração do setor saúde, os municípios estão divididos em 19 Coordenadorias Regionais de Saúde (CRSs), que têm o objetivo de implementar as políticas públicas em nível regional. A cada CRS corresponde uma CIES (Quadro 1).

As áreas de abrangência de cada CIES no estado do Rio Grande do Sul estão demonstradas no Quadro 1.

Quadro 1

\begin{tabular}{|c|c|c|}
\hline \multicolumn{3}{|c|}{ Áreas de abrangência das CIESs } \\
\hline Macrorregião Sanitária & CRS/CIES & Município-sede \\
\hline \multirow[t]{3}{*}{ I - Região Metropolitana } & 1 a CRS & Porto Alegre \\
\hline & $2^{\text {a }}$ CRS & Porto Alegre* \\
\hline & $18^{\mathrm{a}} \mathrm{CRS}$ & Osório \\
\hline \multirow[t]{2}{*}{ II - Região Centro-Oeste } & $4^{\mathrm{a}} \mathrm{CRS}$ & Santa Maria \\
\hline & $10^{\mathrm{a}} \mathrm{CRS}$ & Alegrete \\
\hline \multirow[t]{4}{*}{ III - Região Missioneira } & $9^{a}$ CRS & Cruz Alta \\
\hline & $12^{\mathrm{a}} \mathrm{CRS}$ & Santo Ângelo \\
\hline & $14^{\mathrm{a}} \mathrm{CRS}$ & Santa Rosa \\
\hline & $17^{\mathrm{a}} \mathrm{CRS}$ & ljuí \\
\hline \multirow[t]{4}{*}{ IV - Região Norte } & $6^{\mathrm{a}} \mathrm{CRS}$ & Passo Fundo \\
\hline & $11^{\text {a }}$ CRS & Erechim \\
\hline & $15^{\mathrm{a}} \mathrm{CRS}$ & Palmeira das Missões \\
\hline & $19^{\mathrm{a}} \mathrm{CRS}$ & Frederico Westphalen \\
\hline V - Região Serrana & $5^{\mathrm{a}} \mathrm{CRS}$ & Caxias do Sul \\
\hline \multirow[t]{3}{*}{ VI - Região dos Vales } & $8^{\mathrm{a}} \mathrm{CRS}$ & Cachoeira do Sul \\
\hline & $13^{\mathrm{a}} \mathrm{CRS}$ & Santa Cruz do Sul \\
\hline & $16^{\mathrm{a}} \mathrm{CRS}$ & Lajeado \\
\hline \multirow[t]{2}{*}{ VII - Região Sul } & $3^{\mathrm{a}} \mathrm{CRS}$ & Pelotas \\
\hline & $7^{\text {a }}$ CRS & Bagé \\
\hline
\end{tabular}

Fonte: CIES/ESP/RS (Torres et al., 2008, p. 29).

*Coordenadoria Regional de Saúde com sede no município de Porto Alegre. 
Já a ETSUS vem sendo estruturada no estado para atuar na formação técnica de nível médio na área da saúde. Simultaneamente ao processo burocrático negociado com as instituições governamentais, a equipe técnica da escola desenvolve ações no sentido de implantar e qualificar a Política de Educação Profissional em Saúde no estado. Integra a CIES estadual, assessora as regiões na elaboração de processos de formação e estabelece aproximação com as escolas técnicas estaduais que mantêm cursos na área da saúde, discutindo seus processos pedagógicos.

Ao longo de 2008, a ETSUS/RS realizou oficinas de sensibilização que se constituíram de encontros regionais em 17 das 19 CRSs, a fim de orientar os trabalhadores da saúde sobre a importância do entendimento do conceito e das estratégias de EPS e de subsidiá-los quanto à participação na CIES de cada região (Machado, Daniel e Reinhardt, 2008).

\section{Percurso metodológico}

Tratou-se de um estudo exploratório, ${ }^{4}$ com abordagem qualitativa, realizado em oito CRSs do Rio Grande do Sul que desenvolvem cursos profissionais ou projetos de educação profissional em saúde e que participaram da oficina de sensibilização promovida pela ETSUS/RS.

Os sujeitos da pesquisa foram selecionados de acordo com os seguintes critérios: ter participado da oficina e ser representante na CIES (regional ou estadual), compondo a amostra de oito técnicos das CRSs e quatro gestores regionais. Considerou-se importante incluir mais dois representantes da gestão estadual, um vinculado à Política de Educação Permanente e outro envolvido com a educação profissional, e dois oficineiros da ETSUS. Somaram-se então 16 sujeitos.

A coleta dos dados primários aconteceu entre os meses de março e junho de 2009 por meio de entrevista semiestruturada, gravada em MP3, após assinatura de termo de consentimento livre e esclarecido pelos participantes. A interpretação dos dados foi realizada mediante análise de conteúdo do tipo categorial e temática.

Trabalhar com categorização abrange elementos ou aspectos com características comuns ou que se relacionam entre si, denominadas de categorias. Este procedimento pode ser utilizado em qualquer tipo de análise em pesquisa qualitativa. Na análise temática o conceito central é o tema, que, de acordo com Gomes (2010, p. 86), "comporta um feixe de relações e pode ser graficamente apresentado através de palavras, uma frase, um resumo". Para o referido autor, esta técnica exige uma análise de unidades de registro em busca de significados que definam os dados coletados. 
A análise do material recolhido tenta atingir três objetivos, segundo Minayo (2010): ultrapassar a incerteza do que o pesquisador percebe estar realmente contido na mensagem; compreender os significados; e integrar dados brutos em descobertas finais, indo além das aparências.

A pesquisa foi aprovada pelo parecer n. 516/08 do Comitê de Ética em Pesquisa da Universidade do Vale do Itajaí (Univali) e pelo parecer n. 443/09 do Comitê de Ética em Pesquisa da Escola de Saúde Pública do Estado do Rio Grande do Sul. Foram cumpridos todos os cuidados éticos estabelecidos pelo Conselho Nacional de Saúde pela resolução n. 196/96 (Brasil, 1996b), que dispõe sobre pesquisas envolvendo seres humanos. E para preservar a identidade dos participantes, eles foram identificados pela letra ' $E$ ' seguida de um número (de 1 a 16), obedecendo ao princípio ético de anonimato.

\section{As potencialidades no processo}

Implantar a Pneps no Rio Grande do Sul tem se constituído um desafio para a ETSUS/RS e para as instituições envolvidas nesse processo. Segundo E5, um dos pesquisados,

a escola, além de orientar e direcionar as ações para serem realizadas nas CRSs de forma descentralizada, exerce seu papel de gestora da educação profissional em saúde no estado e de formadora de recursos humanos para o SUS (E-5).

A receptividade dos profissionais atuantes no setor de saúde pública se apresenta como elemento facilitador nesse percurso. Especificamente quanto à atuação da ETSUS/RS, os entrevistados dizem ter muitas expectativas de que a educação profissional em saúde seja consolidada no estado. E-1 e E-10 relatam:

A ETSUS está num momento inicial interno e que a implementação das ações mais efetivas nas regiões será realizada em momento posterior (E-1).

A expectativa é a melhor possível, acentuando que a promoção de uma educação técnica de caráter significativo, com foco na problematização, é um avanço em termos de proposta pedagógica no estado (E-10).

Ao dar ênfase a uma prática pedagógica inovadora, voltada para a lógica da educação permanente em saúde, E-10 reforça a ideia de que o processo pedagógico na educação permanente visa à construção do saber do indivíduo com base no estímulo ao ato reflexivo, tornando o sujeito ativo nas 
transformações da sociedade. Nessa perspectiva, E-9 destaca a relevância da educação permanente no processo de transformação das práticas cotidianas:

A educação profissional em saúde tem muito potencial para promover uma mudança importante em termos de qualidade, principalmente pelo grande contingente de pessoas envolvidas e com potencial. A educação profissional tem um potencial para promover uma transformação (E-9).

Sobre essa questão, Pinheiro e colaboradores (2003) referem ser importante os profissionais qualificarem suas habilidades e competências para atuarem de forma consciente e reflexiva diante das reais necessidades e prioridades de saúde da população. Reconhecem, assim, a capacidade propulsora de gerar e conduzir processos transformadores no campo da saúde.

O crédito dado à formação de trabalhadores de nível médio facilita a implementação da Peps e contribui para a adesão de pessoas aos cursos promovidos. Para E-14, um aspecto facilitador é o desenvolvimento de atividades em locais próximos às residências dos alunos e geralmente em turnos fora do horário de trabalho, considerando que muitos municípios são pequenos e têm dificuldades de liberar os funcionários.

Acredito que tenha uma ação direta na medida em que o curso acontece em um município e o aluno vai lá participar. Lembro-me do curso de saúde mental. Era sexta de noite, sábado, manhã e tarde, e domingo pela manhã. E as pessoas estavam todas lá (E-14).

Os trabalhadores de nível médio, em sua maioria, não conseguem prosseguir seus estudos devido ao fato de muitos cursos serem oferecidos em grandes centros urbanos, dificultando o acesso, principalmente daqueles que não podem se afastar do local de trabalho ou não têm condições financeiras para pagar deslocamento e alimentação. A oferta dentro de um sistema regionalizado soluciona esse problema porque, nesse caso, os cursos costumam ocorrer em horários não coincidentes com os turnos de trabalho e normalmente em fins de semana.

A ideia é que estes cursos aconteçam nas regionais, onde não precisa deslocamento para a capital. Facilitará muito o trabalho e a organização dos próprios municípios. A secretaria estadual tinha todo o direcionamento para quem tinha nível superior. E agora com essa nova sistemática a própria escola vai investir bastante na parte técnica. Estava-se trabalhando o telhado e não a base (E4).

Para promover o desenvolvimento das equipes de saúde da família, a qualificação profissional dos trabalhadores de nível médio é fundamental, 
pois potencializa o desenvolvimento de ações de prevenção de doenças e agravos à saúde da população. O trabalhador qualificado proporciona melhor acesso e práticas adequadas à população atendida, aumentando o vínculo, o acolhimento e a responsabilização dos serviços de saúde, melhorando, portanto, a qualidade de vida da população. O trabalho descentralizado é o grande diferencial destacado por E-14:

Acho que a garantia das políticas de educação profissional em saúde a técnicos de nível médio, inserida nas propostas regionalizadas, fortalece a região, os profissionais e o SUS. E o fortalecimento do SUS passa pela formação de seus profissionais (E-14).

O espaço de mudanças, por meio da formação profissional técnica de nível médio, de forma regionalizada e no âmbito da integralidade, são questões abordadas com ênfase pelos profissionais da saúde participantes da pesquisa, que destacam que o SUS será realmente fortalecido se a formação incluir as necessidades de contexto e as demandas do processo de mudança.

Diversos outros aspectos relacionados à complexidade do processo de implantação e implementação da Pneps são citados. O financiamento, o entrosamento e o interesse dos atores sociais (gestores, trabalhadores, instituições de ensino e movimentos sociais), além do acesso ao Cogere, são considerados grandes facilitadores.

Os entrevistados demonstram entender que esse processo é um passo muito importante para a efetivação e a melhoria na qualidade dos serviços do SUS. Conforme relata E-1,

ter um recurso garantido para fazer as capacitações, para formar recursos humanos, tanto para a educação permanente como para a educação profissional, é uma facilidade (E-1).

O financiamento possibilita que os gestores consigam realizar encontros e reuniões entre os diversos segmentos da Pneps. Dessa maneira, propicia que os atores se articulem e troquem experiências, criando um ambiente favorável para a solução dos problemas de cada região. Como salientam Oliveira e colaboradores (2006), a proposta está em se construírem políticas locais, com processos de mudanças em espaços concretos e favoráveis para uma transformação. A aplicação dessa proposta, segundo E-4, é facilitada pelo financiamento, que estimula os municípios a incentivar a adesão dos trabalhadores.

Se não fosse o recurso, seria muito difícil. Qualquer tipo de capacitação, de seminário, de reunião, envolve recurso. Se os municípios tivessem que pagar, a dificuldade seria muito maior (E-4). 
De acordo com o Conselho Nacional de Secretários de Saúde (Brasil, 2007b, p. 74), “qualquer política só pode ser desenvolvida através da destinação de recursos". E é o financiamento que possibilita, principalmente aos municípios menores e distantes dos grandes centros urbanos, investir em seus trabalhadores para que eles obtenham maior desempenho nas atividades cotidianas, melhorando assim os serviços prestados e o sistema de saúde como

O recurso vindo para o município da regional já é uma facilidade. No ano passado, tivemos um município que ficou responsável. Dividimos as capacitações: uma região ficou com o nível médio e a superior aqui. A cada ano, colocamos em votação. É bom que não fique sempre no mesmo município (E-14).

A respeito da mesma questão, E-9 destaca a facilidade representada pela descentralização do financiamento para as regiões no estado do Rio Grande do Sul, quando aponta que o financiamento garantido oferece mais segurança para as ações realizadas nas regionais:

A maneira que mudou agora, dentro da portaria GM/MS 1.996, que o recurso vem para a região e ela executa, melhorou imensamente. Porque a gente trabalhou muitos anos sem nada de recursos e isto desacreditou. Fizemos um grande investimento e não tivemos retorno no primeiro momento. Com o recurso, as pessoas se motivam a elaborar seus projetos (E-9).

Corroborando as falas dos entrevistados, Silva e Dobashi (2006) dizem ser importante pensar estratégias de financiamento em todas as esferas de gestão, que priorizem a descentralização e a regionalização e qualifiquem os serviços de saúde nas locorregiões - entendidas como espaços de articulação interinstitucional e de negociação para a construção de projetos de educação.

Vale ressaltar que é do Cogere a decisão sobre qual município será o gestor do recurso regional, mas é importante que haja rodízio entre eles, para que todos possam experimentar esse processo.

Outro fator apontado como facilitador para a implementação das ações, segundo os entrevistados, é o bom relacionamento entre os atores e o interesse em participar do processo, como salientam E-1 e E-7:

O bom relacionamento que a gente tem construído com os atores é uma facilidade (E-1).

Eu vejo assim, a integração na CIES, uma facilidade (E-7).

Os entrevistados no estudo demonstraram conhecimento sobre a Política Nacional de Educação Permanente em Saúde. Percebe-se, por suas falas, 
que o envolvimento e o interesse dos atores dos segmentos da Pneps são grandes facilitadores para se pensar e construir perspectivas de mudanças de forma integrada, em espaço aberto, democrático, dialógico, proporcionado pela CIES e pelo Cogere, o que é um grande avanço. A respeito disso, Feuerwerker e colaboradores (2000) enfatizam que as parcerias entre os diversos segmentos da Pneps se constituem em redes de interseção e por isso posibilitam a construção de novos olhares, saberes e práticas diversas.

E-1 e E-16 destacam o bom relacionamento, especificamente com relação ao Cogere:

Outra facilidade que temos é a proximidade com o Cogere, para se discutir as questões que são pertinentes tanto para a educação permanente como para a educação profissional (E-1).

De positivo, a participação dos municípios. É interessante quando são convocados para ajudar, para pensar, gostam disso. $\mathrm{O}$ fato de construírem juntos faz com que se apropriem do espaço. E aí as propostas de educação saem do jeito que eles precisam. Acho que isto é a maior facilidade (E-16).

Para Oliveira e colaboradores (2006), é preciso ampliar os espaços de diálogo e sensibilização de todos os atores envolvidos nesse contexto para sua corresponsabilização, no que diz respeito à formação e ao desenvolvimento de trabalhadores quanto à prestação de cuidados em saúde, visando construir um novo modo de organizar e praticar a atenção à saúde, com essas ações orientadas de acordo com as necessidades da população.

Barreto e colaboradores (2006), em reforço às falas anteriores, enfatizam a relevância da participação dos gestores no processo de formação de profissionais, de acordo com as necessidades das regiões, pois essa questão não se limita ao campo dos serviços, mas também do território, bem como do sistema de saúde como um todo, da necessidade de mudanças das práticas sanitárias, o que pode vir a melhorar os indicadores na busca de uma construção de esforços coletivos transdisciplinares e intersetoriais - permitindo a transformação da rede de serviços de saúde existente no município em espaços de educação contextualizada e de desenvolvimento profissional.

Jesus (2006) acentua que, nesse modelo de gestão, devem ser implementadas ações que se caracterizem como decisão política. $\mathrm{O}$ ator que assina o projeto de seu modelo de gestão (e de formação) tem que possuir conhecimentos acerca de que sistema ele está querendo implantar. É necessário ter subsídios teórico-metodológicos e suporte técnico-operacional para disparar o processo de implementação desse modelo, buscando atender às demandas da população. 
No entanto, também é importante que o trabalhador queira ser agente de mudança. Essa é uma facilidade apontada por alguns entrevistados, traduzida pela participação efetiva de todos os níveis:

Se o servidor naquele dia quer ter um dia de folga, não muda nada. Porque ele vai lá, vai ouvir o blá-blá-blá e continuará fazendo as mesmas coisas. Ele tem que querer ser um agente de mudanças (E-5).

Em síntese, o trabalhador em formação deve se sentir transformado.

Outra facilidade é a aproximação com as instituições de ensino envolvidas com formação em cada região, como aponta E-7:

A facilidade que acho muito importante é a questão do serviço de saúde, poder sentar e dizer como se quer! O SUS está contratando um serviço e este tem que ser assim! (E-7)

E7 acrescenta que a estratégia de educação permanente nas instituições de ensino permite superar o antigo paradigma centrado na ideia de complexos hospitalares para efetivar e potencializar modelos qualitativos no processo de trabalho em saúde. Feuerwerker e colaboradores (2000) entendem que a interação entre serviços e instituições de ensino, em nível local, constrói parceria entre universidades, serviços de saúde e comunidade para a educação permanente dos profissionais. Segundo os autores, na construção dessas relações de parceria não se pode repetir práticas anteriores de integração docente-assistencial, como as relações unilaterais e verticais, com predomínio absoluto da universidade, tratando os serviços apenas como cenários e a população como objeto de intervenção e estudo.

Pelos depoimentos dos entrevistados se percebe o quanto ainda deve ser trabalhada, nas instituições de ensino, a lógica da educação permanente. Nesse sentido, é fundamental a participação das instituições de ensino nas discussões juntamente com as CIESs, para que seja possível avançar na Pneps.

Uma das estratégias é trazer as instituições de ensino para dentro das discussões das CIESs para que cada vez mais se atenda ao objetivo-chave do Pacto de Gestão, de tentar discutir e influenciar na graduação, discutir com as instituições de ensino. Queremos que a instituição de ensino discuta saúde pública (E-12).

Importante destacar a pesquisa realizada em 2008-2009 pela Rede Observatório de Recursos Humanos em Saúde no Rio Grande do Sul e pela ESP/RS, referida por Silva e colaboradores (2009), que constatou em 11 instituições de ensino superior uma crescente mudança nos currículos de 
74 cursos na área da saúde. Os resultados do estudo apresentaram uma gradativa melhora nos cursos de graduação em saúde, em relação à fragmentação ensino/serviço e à progressiva adequação das práticas educativas aos princípios e às diretrizes do SUS.

A partir da implantação de novos currículos, que buscam aproximar ensino e serviço, espera-se que os futuros profissionais atuem na rede com uma visão mais orgânica e contextualizada do trabalho. Isso significa alicerçar sua formação com novas estratégias e competências para que atuem como agentes corresponsáveis pela resolubilidade do sistema (Silva et al., 2009).

De acordo com Lopes e colaboradores (2007), a efetividade da educação permanente em saúde como política para o SUS depende da interlocução das instituições de saúde e de educação e da capacidade destas de desenvolverem ações descentralizadoras por toda a rede de serviços. A descentralização da gestão do processo de formação e de desenvolvimento dos profissionais para uma base local vem atender à ideia da autonomia para os municípios e regiões.

\section{Dificuldades no percurso}

Muitas foram as dificuldades apontadas quanto ao processo de implementação da Pneps no Rio Grande do Sul, a começar pela demora na descentralização das atividades da ETSUS, o que, segundo E-7, causa certa ansiedade nas regiões:

A gente compreende. Mas isto desgasta um pouco. Por exemplo, estamos (...) querendo fazer uma formação para agentes comunitários de saúde. Aí a ETSUS diz: "Segurem, que a gente quer fazer." E aí a gente não faz. Não conseguem fazer e nós não conseguimos fazer. A gente entende que é complicado.

A morosidade no processo de credenciamento da ETSUS/RS, fator de impedimento para que se efetivem as ações na formação dentro da Pneps, principalmente no que diz respeito à formação de trabalhadores de nível médio nas equipes de saúde da família, é apontada por E6: "Entendo que a burocracia é um entrave, mas acho muito lento o processo."

A demora na implantação de cursos técnicos da ETSUS também se deve à falta de recursos humanos e materiais que são requisitos para o credenciamento no CEED. Por se tratar de uma escola técnica, a ETSUS obedece à regulação do setor da saúde e deve seguir as normativas da Secretaria Estadual de Educação e do CEED, ficando sujeita a um processo muitas vezes lento para a execução de cursos, como comenta E-8: 
A portaria GM/MS n. 1.996/2007 estabelece recursos do Ministério da Saúde. Mas não conseguimos executar [o recurso], porque existe toda uma regulação do Fundo Estadual de Saúde, resoluções do Estado que interferem no trabalho da escola. Não se consegue deslocamento e nem pagar diárias. Não conseguimos pagar professor, mesmo que esteja no projeto (E-8).

A legislação estadual por vezes não atende às propostas constantes dos projetos que são aprovados e financiados pelo Ministério da Saúde. Torres e colaboradores (2008) salientam que um dos grandes desafios da Pneps é a questão do financiamento para liberação de projetos que deverão ser realizados por meio de processos licitatórios, o que muitas vezes prejudica a implementação das ações. Além disso, a ETSUS/RS enfrenta dificuldades com falta de pessoal:

Não existe nenhuma pessoa nomeada para a ETSUS. As pessoas ou são da ESP ou são do [Centro de Saúde-Escola] Murialdo. São menos de seis pessoas neste trabalho que é gigantesco. Isto é um problema que dificulta e imobiliza muitas coisas que a gente poderia fazer (E8).

Sobre essa questão, Machado (2008) assevera que, para que as propostas pedagógicas da ETSUS se tornem realidade, será preciso repensar a organização da própria escola que se pretende ser descentralizada.

Às vezes a gente faz ' $n$ ' coisas... Se a gente pudesse trabalhar só com a educação... Na verdade, a gente faz muitas coisas dentro da regional, muitos programas, muitas ações... (E-2).

Para E-9, essa situação é bastante complexa e mexe não só com a ETSUS, mas também com todas as outras políticas:

Não vejo aqui na CRS muita possibilidade de ter pessoas que sejam um braço da ETSUS. (...) Há anos que não há concurso. Tem muitas pessoas que se aposentaram. A maioria das pessoas, por não ser da área da educação, não se interessa. Não sabem o que fazer, nem como fazer. Não há motivação salarial, nem de valorização (E-9).

Os comentários de E-9 convergem para a constatação feita pelo Conselho Nacional de Secretários de Saúde de que a gestão dos recursos humanos nas três esferas de gestão do SUS apresentam muitos problemas de caráter quantitativo e qualitativo (Brasil, 2007c).

Mesmo reconhecendo todas as dificuldades encontradas para implantação e implementação da Política de Educação Profissional em Saúde, a ETSUS/RS está sempre atenta para auxiliar no desenvolvimento dessa política. 
Precisamos ver o pessoal para dar aula lá. Essa é a função da escola. Isso que vai fomentar o desempenho. Mas a escola não vai estar lá. Não tem estrutura, nem de recursos humanos e nem financeiros. Tem que ser um meio, uma facilitadora para conseguir, e nunca um fim (E5).

Na avaliação de E-13, as dificuldades são muitas. Ele coloca em dúvida se realmente haverá modificações nos serviços prestados:

É... Facilidades não são muitas, não. É só porque é o novo. (...) A gente está só no papel [ETSUS]. Imagino que na prática vai ser difícil. Todo mundo está na rede, só que sem qualificação. Vai qualificar a prática. Mas não se sabe se vai modificar muito o serviço em si (E-13).

A preocupação de E-13 é discutida por Albuquerque e colaboradores (2008), que defendem a possibilidade de transformar as práticas profissionais, porque perguntas e respostas são construídas mediante a reflexão, principalmente do trabalhador/aluno sobre o trabalho que realiza ou para o qual se prepara. Daí a lógica da educação permanente, da conscientização crítica e reflexiva, com base nos problemas enfrentados na realidade, levando em consideração os conhecimentos e as experiências adquiridas.

Outro obstáculo descrito se refere ao desconhecimento dos secretários de saúde municipais sobre a Pneps. Segundo E-6, a dificuldade é convencer o gestor do município a liberar servidores para o curso: “O município pequeno tem um funcionário apenas para diversos programas. A dificuldade maior é a liberação do funcionário para fazer o curso, estudar." Para E-7, essa situação pode ser explicada pela carência de profissionais que atuam em determinados municípios:

As equipes são pequenas. É difícil estar tirando sempre os mesmos do município. Quando a gente chama, eles vêm. Vai fazer formação de nível técnico? Às vezes é só ele. Às vezes é o único médico da cidade. Então é essa a dificuldade que a gente tem de tirar. Acho isso complicado (E-7).

Uma situação relatada pelos entrevistados e que necessita de um olhar mais atento da ETSUS/RS se refere à formação dos agentes comunitários de saúde (ACS) e dos auxiliares de saúde bucal (ASB). Isso porque são trabalhadores fundamentais na composição das equipes de saúde da família.

Segundo Müller (2006, p. 1), a lei federal n. 10.507 criou a profissão de agente comunitário de saúde, que deixou de ser uma ocupação para ser uma profissão. Todavia, o autor ressalta que no Brasil "não existe profissão de nível elementar, o mínimo exigido para uma formação é o nível técnico. Portanto, preconizar formação básica (elementar) para o ACS é descumprir 
a legislação". Para os entrevistados, a qualidade das atividades dos agentes comunitários e dos agentes sanitários é imprescindível para melhorar o atendimento do sistema de saúde à população.

O agente comunitário é o que está no dia a dia nas casas e traz a demanda para a unidade. E a unidade se reúne e faz uma análise da situação. E, às vezes, ele tem que voltar lá através da visitação do técnico, da enfermeira ou até do médico. Tudo isso aí é tarefa do agente comunitário. E a maior parte da equipe é de agentes comunitários. Se eles nunca forem treinados, que respaldo ele vai dar para quem é dentista, quem é médico e quem é enfermeiro? Ele que é os olhos da equipe (E-4).

Para a formação de ACS, é importante envolvê-los com outros atores, discutindo, articulando, por meio de uma formação descentralizada, de modo a possibilitar a esse profissional refletir e desenvolver o saber. Os ACSs, segundo Oliveira e Freitas (2006), por sua integração na comunidade e aceitação dela, constituem-se no principal elo dos serviços de saúde com a comunidade, porque vivenciam a realidade dos usuários.

Essa preocupação se justifica em estudo apresentado pelo Conselho Nacional de Secretários de Saúde (Brasil, 2007b), o qual aponta que a formação de recursos humanos de nível médio é importante para o SUS, principalmente para programas como a Estratégia Saúde da Família, citando como exemplo o agente comunitário de saúde. Ferreira, Schimith e Cáceres (2010) ressaltam a necessidade de qualificação de profissionais para trabalhar nos programas de ESF, principalmente de nível médio.

Os depoimentos de E-7 e E-9 enfatizam a dificuldade encontrada para a formação de trabalhadores de nível médio nos municípios, uma vez que não existe pessoal concursado na função de auxiliar de saúde bucal:

Isto é problema. Quando fomos fazer o curso de auxiliar de saúde bucal [ASB], tivemos vários problemas. Primeiro: a gente não encontrou ASBs concursados que tivessem estabilidade. Formam profissionais para a rede SUS e eles não são concursados (E-7).

Olha, para os técnicos de enfermagem, a gente conseguiu rapidinho fechar as duas turmas. Ficaram muito felizes por terem sido lembrados. Mas para formar as turmas de ASB foi bem difícil (E-9).

Segundo Warmling, Damião e Pezzatto (2008), o fato de no Rio Grande do Sul majoritariamente as equipes de saúde da família serem da modalidade I, e ainda algumas delas atuarem sem formação, aumenta a procura dos municípios para a formação desses trabalhadores. Mas a ideia é preparar 
para a formação de técnicos em saúde bucal, o que consolidaria a Política Estadual de Saúde Bucal.

A distância que ocorre entre educação e trabalho é grande, conforme E-1 e E-5, em relação à execução de projetos formativos, o que foi apontado também como dificuldade no processo de implantação e implementação da Política de Educação Profissional no Estado.

Nós temos dois tipos de instituição de ensino na nossa regional: uma aceita a necessidade de colocar os docentes do serviço; a outra não. Acha que o docente ideal é o de academia. De certa forma, o curso pode ficar muito teórico, nada voltado para a realidade da população e nem para o SUS (E-1).

A instituição de ensino ofereceu um pessoal com doutorado, pós-doutorado. E perguntei a esse professor se alguma vez ele entrou numa unidade básica de saúde, para ver como é que funciona, como é que é a sua complexidade (E-5).

E-13 critica a desarticulação entre a teoria trabalhada pelas universidades e a prática relacionada aos serviços públicos de saúde:

Sempre na reunião está tudo muito bem. Eles [representantes das instituições de ensino] gostam do enfoque, contribuem com o que a gente fala e tudo. E a gente pede para seguir o projeto e tem sempre enraizado no modelo tradicional, que não tem nada de ensino em serviço (E-13).

Outro problema levantado é em relação ao pagamento de docente/trabalhador, como observa E-9: “Como vou remunerar o docente se está em horário de trabalho? E está recebendo de duas fontes ao mesmo tempo? É o grande problema." Torres e colaboradores (2008) consideram esse aspecto como um entrave para a implementação da Pneps.

Para E-11, também representa dificuldade a rotatividade de representantes dos segmentos nas CIESs regionais, com a descontinuidade no processo de EPS:

Na CIES, há vários atores sociais, instituições, segmentos. A pessoa que está representando já tem uma caminhada junto. E o que acontece? Esta pessoa é substituída por outra. E até que a próxima tenha a mesma caminhada, a mesma sensibilização, a mesma disponibilidade. Então a descontinuidade é uma dificuldade (E-11).

Na opinião de E-15 e E-12, o maior entrave na operacionalização da Pneps “é a distância entre o planejamento e a execução" (E-15) e a própria operacionalização do fluxo. 
A portaria permite tudo. E os fundos não permitem nada. Então quando está na hora de contratualizar com as instituições de ensino, nada pode. E cada vez mais a gente percebe que quando se trata de curso a gente só tem que encaminhar para licitação (E-12).

Silva e Dobashi (2006) ressaltam que os municípios brasileiros são os principais executores das políticas de saúde. Portanto, é necessário que eles dinamizem sua relação com as várias instâncias, mantendo a corresponsabilização entre os segmentos da formação na Pneps e selando compromissos com uma gestão democrática e dialógica, voltada para a qualidade de vida da população brasileira.

\section{Considerações finais}

Com base nos depoimentos dos entrevistados, pode-se afirmar que eles acreditam serem possíveis as ações de implantação e implementação da Pneps, porque existe financiamento do Ministério da Saúde. Consideram também como potencializador o bom acesso junto ao Cogere e o envolvimento de todos os segmentos da formação. Em relação às dificuldades, deu-se ênfase à falta de recursos humanos no estado, o que dificulta o trabalho em nível central na ETSUS/RS e também nas Coordenadorias Regionais de Saúde e resulta, atualmente, em grande acúmulo e sobrecarga para seus trabalhadores.

Os principais entraves citados se referem à operacionalidade do fluxo para a execução entre o projeto e o seu cumprimento e à necessidade das ações da ETSUS no estado, em virtude da grande demanda para qualificação/certificação de trabalhadores de nível médio na área da saúde, principalmente para atender a Estratégia Saúde da Família.

O conhecimento produzido com base neste estudo permite sugerir que todos os esforços sejam empenhados pelas instituições responsáveis, no sentido de acelerar o processo de credenciamento da ETSUS no CEED, visto ser essa etapa estratégica para a operacionalização, no estado, de cursos técnicos em saúde de caráter público. No que tange à execução da Pneps, é preciso que sejam criados mecanismos técnicos e administrativos que agilizem o fluxo dos processos formativos das regiões, desde a sua apresentação até a sua operacionalização.

Esta pesquisa também provocou reflexões sobre a qualificação dos trabalhadores da saúde de nível médio, baseada na integração ensino e serviço, com propostas metodológicas problematizadoras. É necessária ampla capacitação dos profissionais para a integração da atividade docente ao trabalho cotidiano de caráter assistencial. Um desafio importante a ser enfrentado diz respeito à remuneração de professores, o que hoje ainda não é legalmente viável. 
Esperamos que este estudo contribua para a continuidade dos debates sobre o processo de implantação e implementação da ETSUS/RS, no sentido de avançar a educação profissional de trabalhadores de nível médio, efetivando a Política Nacional de Educação Permanente em Saúde no Estado do Rio Grande do Sul.

Entendemos ser fundamental que a implementação da Pneps no estado fomente a incorporação, de forma consistente e definitiva, da formação profissional em saúde como elemento indispensável à gestão do sistema de saúde como um todo. É essencial maior investimento em infraestrutura e em recursos humanos para que a formação profissional de nível médio ocorra de forma contínua e a rede de ensino responda com cursos regulares às necessidades do SUS.

\section{Colaboradores}

Hedi Berwaldt Daniel concebeu este artigo e foi sua principal redatora. Juliana Vieira de Araujo Sandri foi a orientadora da dissertação e contribuiu na organização textual. Luciane Peter Grillo auxiliou na análise dos dados e na revisão do texto. 
Resumen La Política Nacional de Educación Permanente en Salud fue creada en 2004 como estrategia del Sistema Único de Salud para la formación de recursos humanos. Una ordenanza del Ministerio de Salud ha establecido directrices para su implementación, fortaleciendo las escuelas técnicas del Sistema Único de Salud como instituciones prioritarias en la articulación y ejecución de la formación de los trabajadores de nivel medio. Este artículo fue elaborado con base en resultados de investigación cualitativa. La recolección de datos consistió en el análisis temático de los documentos de los talleres de sensibilización y entrevistas aplicadas a gestores regionales, estatales y técnicos de las coordinaciones regionales de salud que participaron en talleres de sensibilización, además de técnicos de la Escuela Estatal de Educación Profesional de la Salud de Río Grande do Sul (Brasil). Los resultados indican que ellos tenían conocimiento de la ordenanza y que las potencialidades estaban en el financiamiento federal, en el acceso al Colegiado de Gestión Regional y en el compromiso de los involucrados. Por otro lado, las dificultades eran la falta de recursos humanos en la Secretaría Estatal de Salud, que ocasionaba la sobrecarga de trabajo; el hecho de que la escuela no sea descentralizada y de no estar acreditada en el estado; la liberación de los trabajadores municipales para la formación y las barreras operativas en la ejecución de los recursos financieros en el estado.

Palabras clave educación permanente; escuela técnica; Sistema Único de Salud.

\section{Notas}

l Secretaria de Estado da Saúde do Rio Grande do Sul, Porto Alegre, Rio Grande do Sul, Brasil.

Mestre em Saúde e Gestão do Trabalho pela Universidade do Vale do Itajaí (Univali). $<$ hedidaniel@hotmail.com>

Correspondência: Rua Casemiro de Abreu, 475, CEP 94480-380, Viamão, Rio Grande do Sul, Brasil.

2 Universidade do Vale do Itajaí, Itajaí, Santa Catarina, Brasil.

Doutora em Enfermagem pela Universidade Federal de Santa Catarina (UFSC).

$<$ jusandri@univali.br>

3 Universidade do Vale do Itajaí, Itajaí, Santa Catarina, Brasil.

Doutora em Ciências Aplicadas à Pediatria pela Universidade Federal de São Paulo (Unifesp).

<grillo@univali.br>

4 Este artigo foi produzido com base na dissertação intitulada Análise da implantação e implementação da Política de Educação Permanente na Educação Profissional em Saúde do Sistema Único de Saúde no Estado do Rio Grande do Sul, de Hedi Berwaldt Daniel. Apresentado em 2009 ao Mestrado Profissionalizante de Saúde e Gestão do Trabalho da Universidade do Vale do Itajaí (Univali), o estudo teve por objetivo revelar a percepção de profissionais atuantes nos CRS, gestores regionais, representantes da gestão estadual e técnicos da ETSUS/RS quanto às potencialidades e dificuldades encontradas no percurso de implantação. 


\section{Referências}

ALBUQUERQUE, Veronica S. et al. A integração ensino-serviço no contexto dos processos de mudança na formação superior dos profissionais da saúde. Revista Brasileira de Educação Médica, Rio de Janeiro, v. 32, n. 3, p. 356-362, 2008.

BARRETO, Ivana C. H. C. et al. Educação permanente e a construção de sistemas municipais de saúde-escola: o caso de Fortaleza (CE). Divulgação em Saúde para Debate, Londrina, n. 34, p. 31-46, maio 2006.

BRASIL. Lei n. 9.394, de 20 de dezembro de 1996. Estabelece as Diretrizes e Bases da Educação Nacional. Diário Oficial da União, Poder Executivo, Brasília, DF, 23 nov. 1996a. Seção 1, p. 27.833-27.841.

BRASIL. Ministério da Saúde. Conselho Nacional de Saúde. Resolução n. 196, de 10 de outubro de 1996. Aprova as diretrizes e normas regulamentadoras de pesquisas envolvendo seres humanos. Brasília, DF, 1996b. Disponível em: <http://bvsms.saude. gov.br/bvs/saudelegis/cns/1996/res0196_10_ 10_1996.html>. Acesso em: 20 nov. 2008.

BRASIL. Decreto n. 2.208, de 17 de abril de 1997. Regulamenta o $\S 2^{\circ}$ do art. 36 e os arts. 39 a 42 da lei n. 9.394, de 20 de dezembro de 1996, que estabelece as diretrizes e bases da educação nacional. Brasília, DF, 1997. Disponível em: <www.planalto.gov. br/ccivil_03/decreto/D2208.htm>. Acesso em: 20 nov. 2008.

BRASIL. Constituição (1988). Constituição da República Federativa do Brasil: 1988. Texto constitucional de 5 de outubro de 1988 com alterações adotadas pelas emendas constitucionais n. 1, de 1992, a 38, de 2002, e pelas Emendas Constitucionais de Revisão de n. 1 a 6, de 1994. 19. ed. Brasília, DF, 2002.

BRASIL. Ministério da Saúde. Política de formação e desenvolvimento para o SUS: caminhos para a Educação Permanente em
Saúde. Secretaria da Gestão do Trabalho e da Educação na Saúde. Departamento de Gestão da Educação na Saúde. 2003. Disponível em: <http://bvsms.saude.gov.br/ bvs/publicacoes/pol_formacao_desenv.pdf $>$. Acesso em: 15 out. 2009.

BRASIL. Ministério da Saúde. Portaria GM/MS n. 198, de 13 de fevereiro de 2004. Institui a Política Nacional de Educação Permanente em Saúde como estratégia do Sistema Único de Saúde para a formação e o desenvolvimento de trabalhadores para o setor e dá outras providências. Brasília, DF, 2004a. Disponível em: <http://dtr2001.saude. gov.br/sas/PORTARIAS/Port2004/GM/ GM-198.htm>. Acesso em: 20 nov. 2008.

BRASIL. Decreto n. 5.154, de 23 de julho de 2004. Regulamenta o $\S 2^{\circ}$ do artigo 36 e os arts. 39 a 41 da lei n. 9.394, de 20 de dezembro de 1996, que estabelece as diretrizes e bases da educação nacional, e dá outras providências. Brasília, DF, 2004b. Disponível em: <www.planalto.gov.br/ccivil_ 03/_Ato2004-2006/2004/Decreto/D5154.htm>. Acesso em: 20 nov. 2008.

BRASIL. Ministério da Saúde. Portaria GM/MS n. 1.996, de 20 de agosto de 2007. Dispõe sobre as diretrizes para a implementação da Política Nacional de Educação Permanente em Saúde e dá outras providências. Brasília, DF, 2007a. Disponível em: <http://bvsms. saude.gov.br/bvs/saudelegis/gm/2007/ prt1996_20_08_2007.html>. Acesso em: 19 nov. 2008.

BRASIL. Conselho Nacional de Secretários de Saúde. Gestão do Trabalho na Saúde. Brasília, DF, 2007b. (Coleção Pró-Gestores: para entender o Pacto de Gestão do SUS, 5. p. 74). Disponível em: <http://189.28.128.100/ dab/docs/publicacoes/conass_progestores/ livro_5_gestao_do_trabalho_em_saude.pdf $>$. Acesso em 19 set. 2009

BRASIL. Conselho Nacional de Secretários de Saúde. Sistema Ùnico de Saúde. 
Brasília, DF , CONASS, 2007c. 291 p. (Coleção Progestores - Para entender a gestão do SUS, 1). Disponível em: <http://bvsms.saude. gov.br/bvs/publicacoes/colec_progestores_ livrol.pdf>. Acesso em: 19 set. 2009.

CAMPOS, Francisco E. et al. Os desafios atuais para a educação permanente no SUS. Cadernos RH Saúde, Brasília, v. 3, n. 1, p. 39-51, mar. 2006.

FERREIRA, Maria E. V.; SCHIMITH, Maria D.; CÁCERES, Nilton C. Necessidades de capacitação e aperfeiçoamento dos profissionais de equipes de saúde da família da $4^{a}$ Coordenadoria Regional de Saúde do Estado do Rio Grande do Sul. Ciência \& Saúde Coletiva, Rio de Janeiro, v. 15, n. 5, p. 2.611-2.620, ago. 2010. Disponível em: <www.scielo.br/ $\mathrm{pdf} / \mathrm{csc} / \mathrm{v} 15 \mathrm{n} 5 / \mathrm{v} 15 \mathrm{n} 5 \mathrm{a} 35 . \mathrm{pdf}>$. Acesso em: 20 out. 2011.

FEUERWERKER, Laura et al. Diversificação de cenários de ensino e trabalho sobre necessidades/problemas da comunidade. $D i$ vulgação em Saúde para Debate, Rio de Janeiro, n. 22, p. 36-48, dez. 2000.

GALVÃO, Ena A. et al. As escolas técnicas do SUS: uma abordagem histórica. Cadernos RH Saúde, Brasília, v. 3, n. 1, p. 61-84, 2006.

GOMES, Romeu. Análise e interpretação de dados de pesquisa qualitativa. In: MINAYO, Maria C. S.; DESLANDES, Suely F.; GOMES, Romeu (Orgs.). Pesquisa social: teoria, método e criatividade. 29. ed. Petrópolis: Vozes, 2010. p. 79-105.

HADDAD, Ana E. et al. Política nacional de educação em saúde. Revista Baiana de Saúde Pública, Salvador, v. 32, supl. 1, p. 98-114, 2008.

JESUS, Washington L. A. SUS-Alagoinhas: um modelo de gestão/atenção para a (trans)formação de sujeitos e coletivos. Divulgação em Saúde para Debate, Londrina, n. 36, p. 61-75, ago. 2006.

LOPES, Sara R. S. et al. Potencialidades da educação permanente para a transformação das práticas de saúde. Comunicação em Ciências da Saúde, Brasília, DF, v. 18, n. 2, p. 147-155, abr./jun. 2007.

MACHADO, Maria E. Necessidades de formação em saúde e políticas educacionais: uma reflexão sobre as tensões entre as políticas de saúde e de educação no estado do Rio Grande do Sul. In: VIAL, Sandra R. et al. (Coords.). A política de educação permanente em saúde: a trajetória no Rio Grande do Sul. Porto Alegre: Escola de Saúde Pública, Secretaria de Estado da Saúde do Rio Grande do Sul, 2008. p. 41-51.

MACHADO, Maria E.; DANIEL, Hedi B.; REINHARDT, Rosemari D. Formação profissional de nivel médio e a criação da Escola Técnica do SUS: no organograma do SUS. In: VIAL, Sandra R. et al. (Coords.). A politica de educação permanente em saúde: a trajetória no Rio Grande do Sul. Porto Alegre: Escola de Saúde Pública, Secretaria de Estado da Saúde do Rio Grande do Sul, 2008. p. 53-60.

MINAYO, Maria C. S.; DESLANDES, Suely F.; GOMES, Romeu. Pesquisa social: teoria, método e criatividade. 29. ed. Petrópolis: Vozes, 2010.

MÜLLER, Julio. A qualificação dos ACS é um imperativo do desenvolvimento social e cultural. RET-SUS, Rio de Janeiro, n. 21, p. 1-3, set. 2006.

OLIVEIRA, André L. et al. Estrutura organizacional como instrumento para a gestão do sistema de saúde do município de Uberlândia (MG). Divulgação em Saúde para Debate, Botucatu, n. 34, p. 47-54, maio 2006.

OLIVEIRA, Gilma B. N.; FREITAS, Claudia H. S. M. Os agentes comunitários e a implementação de ações de saúde bucal: superando desafios para a promoção da saúde. Divulgação em Saúde para Debate, Botucatu, n. 34, p. 55-62, maio 2006 .

PINHEIRO, Eliana F. C. et al. Profissional de saúde: a inter-relação entre formação e prática. Formação, Brasília, DF, n. 8, p. 45- 55, 2003. 
SILVA, Lucia S. et al. A formação de recursos humanos na graduação em saúde compatibilizando os distintos tempos entre saberes e práticas: um desafio emergente do SUS. In: BELLINI, Maria I. (Coords.). Rede Observatório de Recursos Humanos em Saúde: a realidade da saúde do estado do Rio Grande do Sul pelo olhar do trabalhador em saúde. Porto Alegre: Secretaria de Estado da Saúde do Rio Grande do Sul, Escola de Saúde Pública, Rede Observatório de Recursos Humanos, 2009.

SILVA, Silvio F.; DOBASHI, Beatriz F. Um novo pacto no SUS. Divulgação em Saúde para Debate, Londrina, n. 34, p. 9-17, maio 2006.

TORRES, Odete M. et al. Caminhos da educação permanente em saúde: a trajetória no Rio Grande do Sul. In: VIAL, Sandra R. et al. (Coords.). Caminhos da educação permanente em saúde: a trajetória no Rio Grande do Sul. Porto Alegre: Escola de Saúde Pública, Secretaria de Estado da Saúde do Rio Grande do Sul, 2008. p. 21-40.
WARMLING, Cristine M.; DAMIÃO, Karla S. L. M.; PEZZATTO, Luciane M. Equidade e qualidade no acesso à saúde bucal: sua relação com a formação e inserção de trabalhadores técnicos de nível médio na saúde bucal. In: VIAL, Sandra R. et al. (Coords.). Caminhos da educação permanente em saúde: a trajetória no Rio Grande do Sul. Porto Alegre: Escola de Saúde Pública, Secretaria de Estado da Saúde do Rio Grande do Sul, 2008. p. 99-106.

Recebido em 29/11/2011

Aprovado em 01/04/2014 